\title{
Elements Diffusion of the Interface for Be/ 00Cr17Ni14Mo2 Stainless Steel by Hot Pressing
}

\author{
Hui Li ${ }^{a}{ }^{*}$, Yingkun Gong, Yilin Chen, Fei Duan and Xuan Wang ${ }^{b}$
}

Chongqing Academy of Metrology and Quality Inspection, Chongqing 401123, China

aLihui@cqu.edu.cn, ${ }^{\mathrm{b} 13667669535 @ 163 . c o m}$

*Corresponding author, Lihui@cqu.edu.cn

Keywords: beryllium, 00Cr17Ni14Mo2 stainless steel, diffusion bonding, element diffusion, interface.

\begin{abstract}
Diffusion bonding is an effective way to join beryllium with other materials. To study the elements diffusion near the bonding interface so that improve the joints performance, the microstructure, and distribution of composition and phase on the interface of Be/00Cr17Ni14Mo2 stainless steel diffusion bonding were analyzed using scanning electron microscopy (SEM), scanning auger microscopy (SAM), x-ray diffraction (XRD), and the elements diffusion on the interface and the relationship between phases distribution and microstructure were also discussed. The results show that the elements diffuse mainly through the surface and the grain boundary, and the grain boundary is the main gateway of the elements diffusion. Dissimilar metal atoms gather first in the grain boundary and form intermetallic compounds, then the metal atoms diffuse through the grain boundaries or intermetallic compounds and the intermetallic compounds grow up on the crystal boundary, so the Be/00Cr17Ni14Mo2 stainless steel diffusion bonding joint is brittle fracture on the grain boundary.
\end{abstract}

\section{Introduction}

In recent years, scholars carried on a lot of research on diffusion bonding of dissimilar metals[1-9]. Beryllium is a reactor material because it has the lowest $Z$, relatively high thermal conductivity, low activation, etc. Diffusion bonding is an effective way to join beryllium with other materials. With the process, joining of materials is achieved through atomic transport and mechanical processes at the bonding interface. It is difficult to bond beryllium with 00Cr17Ni14Mo2 stainless steel, because beryllium is very brittle, and beryllium with the main elements of $00 \mathrm{Cr} 17 \mathrm{Ni} 14 \mathrm{Mo} 2$ stainless steel easily form brittle intermetallic compounds in the process of diffusion bonding. Therefore, to improve bonding performance, researching the elements diffusion is important on the interface. In this paper, the elements diffusion on the interface of Be/00Cr17Ni14Mo2 stainless steel diffusion bonding in terms of the microstructure and the distribution of composition and phase have been investigated.

\section{Experimental Procedure}

\section{Materials and Specimens}

Beryllium specimens are made of hot-pressed beryllium, which composition show in Table 1 . The 00Cr17Ni14Mo2 stainless steel (SS) is the austenite anti- hydrogen stainless steel and the impurity total contents is less than $0.17 \%$, which the main alloying elements content show in Table 2 . Bars of beryllium and SS are $10 \mathrm{~mm}$ in diameter and $5 \mathrm{~mm}$ in height. Diffusion bonding was achieved by hot pressing at $60 \mathrm{MPa}$ and $750^{\circ} \mathrm{C}$ in $10^{-3} \mathrm{~Pa}$ vacuum, and the holding time is $2 \mathrm{~h}\left(750^{\circ} \mathrm{C} / 50 \mathrm{MPa} / 2 \mathrm{~h}\right)$.

Table1. The content of heat pressed Be powder, w/\%

\begin{tabular}{ccccccccc}
\hline $\mathrm{Be}$ & $\mathrm{Fe}$ & $\mathrm{Al}$ & $\mathrm{Ni}$ & $\mathrm{Cr}$ & $\mathrm{Mn}$ & $\mathrm{Pb}$ & $\mathrm{Mg}$ & $\mathrm{O}$ \\
\hline Bal. & 0.18 & 0.078 & 0.003 & 0.01 & 0.013 & 0.001 & 0.12 & 0.75 \\
\hline
\end{tabular}


Table2. The content of SS, w/\%

\begin{tabular}{ccccc}
\hline $\mathrm{Fe}$ & $\mathrm{Cr}$ & $\mathrm{Ni}$ & $\mathrm{Mo}$ & $\mathrm{Mn}$ \\
\hline Bal. & 17.2 & 14.27 & 2.19 & 1.05
\end{tabular}

\section{Instruments and Experiment Method}

The microstructure were recorded using KYKY-1000B scanning electron microscopy (SEM). The XRD pattern were recorded using D/MAX-1200 X-ray diffraction (XRD), at a Cu-anode, 40kV tube voltage, $30 \mathrm{~mA}$ tube current and $2^{\circ} \mathrm{min}^{-1}$ scanning speed. The SAM spectra were recorded using PHI650SAM scanning auger microscopy, at 3kV electron excitation energy, $0.25 \%$ energy resolution, $100 \mathrm{nA}$ electron beam current. The distributions of elements near the Be/SS bonding interface were measured along the axial direction of diffusion bonding by AES

\section{Results and Discussion}

\section{Experimental}

To study the phases distribution of the whole joints for Be/SS diffusion bonding, the layer peeling on the interface was carried out by XRD from the beryllium side to the SS side. The bottom of Fig. 1 is the starting position of peeling layer, which is about $0.93 \mathrm{~mm}$ to the SS side. The XRD patterns of beryllium without hot pressing and the successive peeling layers of the joints show in Fig. 2, which main phase are $\alpha$-Be (beryllium base solid solution) and $\gamma$-Fe (iron based solid solution), less amount phases are $\mathrm{Be}_{11} \mathrm{Fe}, \mathrm{Be}_{5} \mathrm{Fe}, \mathrm{FeBe}_{2}$, and trace phases are $\mathrm{Be}_{21} \mathrm{Ni}_{5}, \mathrm{Be}_{12} \mathrm{Cr}, \mathrm{MoBe}_{12}, \mathrm{NiBe}$. However, XRD phase analysis requires that there is a certain amount of phase in the sample, and phase content is too less to be detected. The phases distribution of defferent distance from beryllium side show in Table 3 on Be/SS diffusion bonding zone.

Table 3.The phases distribution of defferent distance from Be side in Be/SS diffusion bonding joint

\begin{tabular}{|c|c|c|c|}
\hline \multirow{2}{*}{$\begin{array}{c}\text { Distance from } \\
\text { beryllium side } \\
(\mu \mathrm{m})\end{array}$} & \multicolumn{3}{|c|}{ Phase composition } \\
\hline & Main phases & Less amount phases & Trace phases \\
\hline $\begin{array}{l}\text { Beryllium } \\
\text { without hot } \\
\text { pressing }\end{array}$ & $\alpha-\mathrm{Be}$ & & $\mathrm{BeO}$ \\
\hline 300 & $\alpha-\mathrm{Be}$ & $\mathrm{Be}_{11} \mathrm{Fe}, \mathrm{Be}_{12} \mathrm{Cr}, \mathrm{BeO}$ & \\
\hline 500 & $\alpha-\mathrm{Be}$ & $\mathrm{Be}_{11} \mathrm{Fe}, \mathrm{Be}_{12} \mathrm{Cr}, \mathrm{BeO}$ & $\begin{array}{l}\mathrm{NiBe} \\
\mathrm{Be}_{21} \mathrm{Ni}_{5}\end{array}$ \\
\hline 700 & $\alpha-\mathrm{Be}$ & $\mathrm{Be}_{11} \mathrm{Fe}, \mathrm{Be}_{12} \mathrm{Cr}, \mathrm{BeO}, \mathrm{NiBe}, \mathrm{Be}_{21} \mathrm{Ni}_{5}$ & $\mathrm{FeBe}_{2}, \mathrm{Be}_{5} \mathrm{Fe}$ \\
\hline 800 & $\alpha-\mathrm{Be}$ & $\mathrm{Be}_{11} \mathrm{Fe}, \mathrm{Be}_{12} \mathrm{Cr}, \mathrm{BeO}, \mathrm{NiBe}, \mathrm{Be}_{21} \mathrm{Ni}_{5}, \mathrm{FeBe}_{2}, \mathrm{Be}_{5} \mathrm{Fe}$ & $\mathrm{MoBe}_{12}$ \\
\hline 900 & $\alpha$-Be, $\mathrm{Be}_{11} \mathrm{Fe}$ & $\begin{array}{c}\mathrm{BeO}, \alpha \text {-Fe, NiBe, } \gamma \text {-Fe, } \mathrm{Be}_{5} \mathrm{Fe}, \mathrm{FeBe}_{2}, \mathrm{Be}_{12} \mathrm{Cr} \text {, } \\
\mathrm{Be}_{21} \mathrm{Ni}_{5}\end{array}$ & $\mathrm{MoBe}_{2}$ \\
\hline 970 (SS side) & & $\gamma$-Fe, $\alpha-\mathrm{Be}$ & \\
\hline
\end{tabular}

The results of the phases analysis are basically consistent with the Fe-Be binary phase diagram[10], which Fe and Be form incomplete solid solution with very little solubility limit, so over saturated solid solution cause forming intermetallic compounds. Fig. $2 \mathrm{~b} \sim 2 \mathrm{f}$ show that the intermetallic compounds of Be and Fe are mainly $\mathrm{Be}_{11} \mathrm{Fe}$ and $\mathrm{FeBe}_{2}$, and less $\mathrm{Be}_{5} \mathrm{Fe} . \mathrm{Be}_{11} \mathrm{Fe}$ is distributed widely in the diffusion bonding zone, which appears in all peeling layer from the beryllium side to the SS side. In the Fe-Be binary phase diagram[10], the range of $\mathrm{Be}_{5} \mathrm{Fe}$ is narrow, so its diffraction peaks are not obvious. Fig. $2 \mathrm{~b} \sim 2 \mathrm{f}$ also show that there are $\mathrm{Be}_{21} \mathrm{Ni}_{5}, \mathrm{Be}_{12} \mathrm{Cr}$, $\mathrm{MoBe}_{12}$, NiBe and so on in the Be/SS diffusion bonding interface, which are much less than $\mathrm{Be}_{11} \mathrm{Fe}$, because the content of $\mathrm{Cr}, \mathrm{Ni}$ and Mo is much less than one of Fe. The results of the phases analysis 
are basically consistent with the $\mathrm{Cr}-\mathrm{Be}, \mathrm{Ni}-\mathrm{Be}$ and Mo-Be binary phase diagram[10], which $\mathrm{Cr}, \mathrm{Ni}$ and Mo with Be form respectively the incomplete solid solution with very little solubility limit, so their over saturated solid solution cause forming intermetallic compounds. Fig. 2b shows that there are $\mathrm{Be}_{11} \mathrm{Fe}$ and $\mathrm{Be}_{12} \mathrm{Cr}$ near the diffusion transition region of beryllium side, which explains that the diffusion distance of $\mathrm{Cr}$ is far and almost consistent with one of $\mathrm{Fe}$ in beryllium, and it is easy to $\mathrm{Cr}$ with Be form intermetallic compounds. Fig. $2 \mathrm{~b} \sim 2 \mathrm{f}$ show that $\mathrm{Be}_{12} \mathrm{Cr}$ exists in a wide range, which is basically consistent with the Cr-Be binary phase diagram[10].

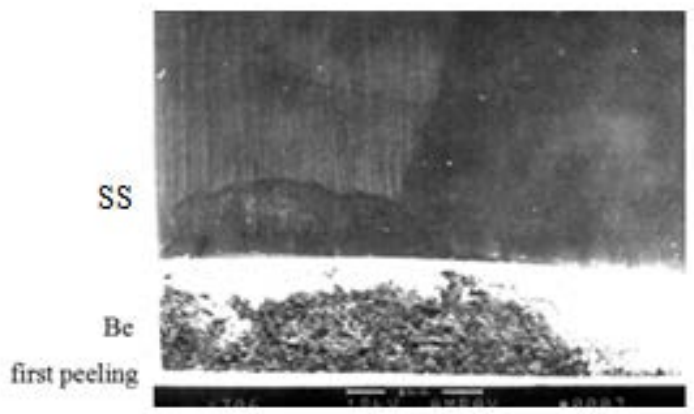

Fig. 1 The first peeling site of the beryllium side

Based on the reaction-diffusion of Be-Cr binary system, we can conclude that the formation enthalpy of $\mathrm{Be}_{12} \mathrm{Cr}$ is less than zero, and its free energy is lower than other intermetallic compounds of $\mathrm{Be}$ and $\mathrm{Cr}$ under this condition. Fig. 2c 2f show that the intermetallic compound of $\mathrm{Be}$ and $\mathrm{Ni}$ is mainly $\mathrm{Be}_{21} \mathrm{Ni}_{5}$, which also exists in a wide range, and basically is consistent with the Fe-Be binary phase diagram[10]. Fig.3 show the distributions of $\mathrm{Fe}, \mathrm{Be}, \mathrm{Cr}$ and $\mathrm{Ni}$ near the Be/SS bonding interface measured using AES, which $\mathrm{Cr}$ and $\mathrm{Ni}$ continue flat into beryllium side, and indicate that they diffuse very far from the SS side, so $\mathrm{Ni}$ is similar $\mathrm{Cr}$ diffusion in the interface. However, the amount of $\mathrm{Be}_{21} \mathrm{Ni}_{5}$ is less, and its partial diffraction peaks overlap the compounds peaks of Be and $\mathrm{Fe}$, so $\mathrm{Be}_{21} \mathrm{Ni}_{5}$ is obviously less than $\mathrm{Be}_{12} \mathrm{Cr}$. Fig. 2e shows that there is trace $\mathrm{MoBe}_{12}$ after peeling $800 \mu \mathrm{m}$ from the beryllium side. $\mathrm{MoBe}_{12}$ and $\mathrm{Be}_{12} \mathrm{Cr}$ are all tetragonal, which lattice constant $a$ and $c$ are respectively 7.251 $\AA, 4.241 \AA$ and $7.233 \AA$ and $4.176 \AA$, so their molecular formula and lattice constant are similar, as well as atomic number, the atomic proportion and the crystal structure are

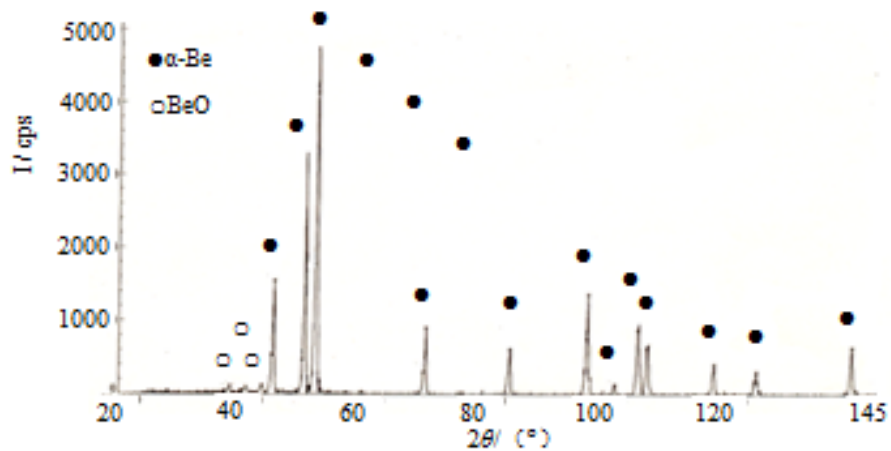

Fig. $2 \mathrm{a} X R D$ pattern of beryllium without heat pressing 


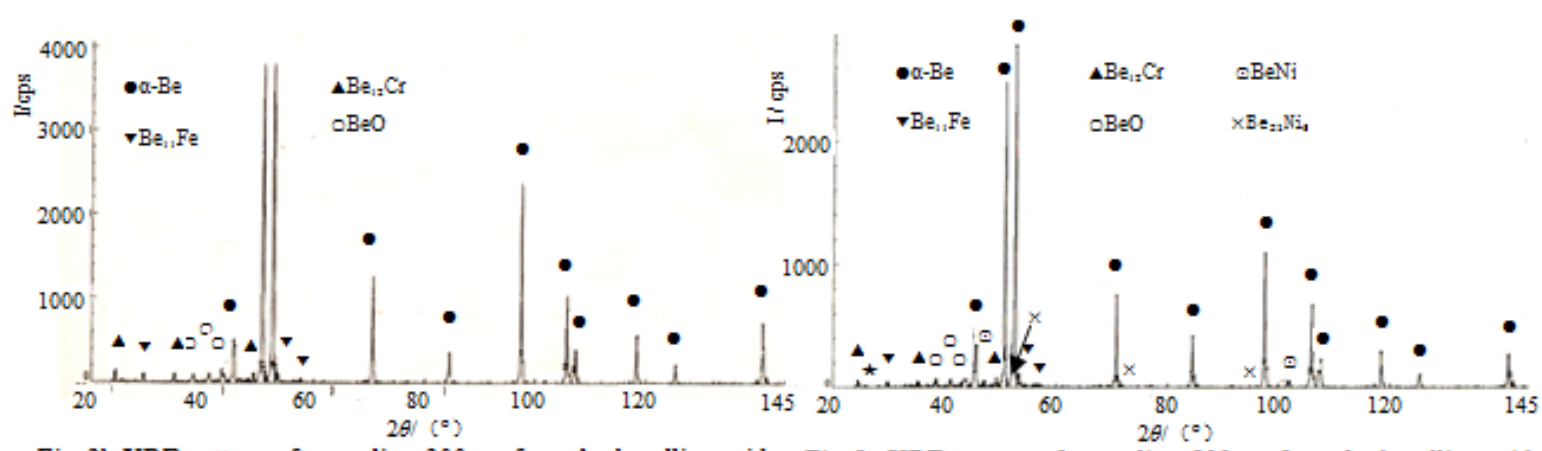

Fig. $2 b$ XRD pattern after peeling $300 \mu \mathrm{m}$ from the beryllium side Fig. $2 \mathrm{c}$ XRD pattern after peeling $500 \mu \mathrm{m}$ from the beryllium side
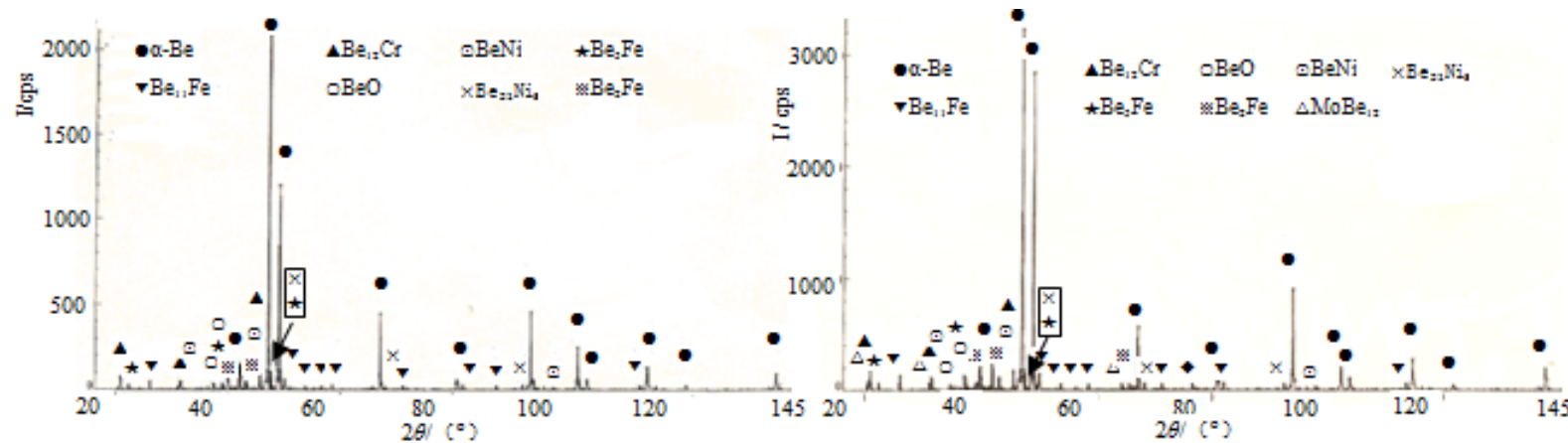

Fig. $2 \mathrm{~d}$ XRD pattem after peeling $700 \mu \mathrm{m}$ from the beryllium side Fig. $2 \mathrm{e}$ XRD pattern after peeling $800 \mu \mathrm{m}$ from the beryllium side
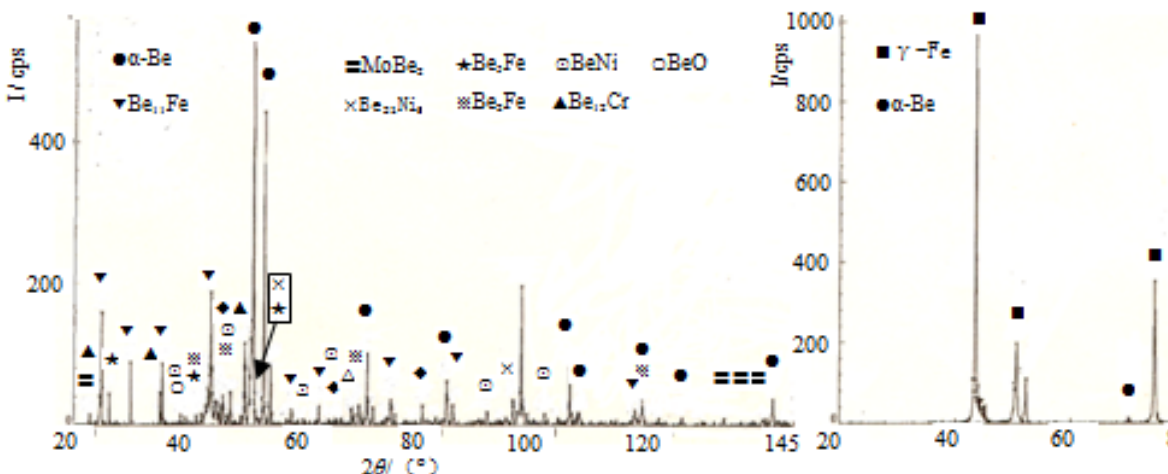

Fig. $2 \mathrm{f} \mathrm{XRD} \mathrm{pattern} \mathrm{after} \mathrm{peeling} 900 \mu \mathrm{m}$ from the beryllium side Fig. $2 \mathrm{~g} \mathrm{XRD}$ pattern after peeling $970 \mu \mathrm{m}$ from the beryllium side

Fig. 2 The XRD patterns after successive peeling layers in Be/SS diffusion bonding zone

same. Therefore, $\mathrm{MoBe}_{12}$ and $\mathrm{Be}_{12} \mathrm{Cr}$ can meet the similar phase dissolution principle, the diffraction peaks of $\mathrm{MoBe}_{12}$ are not obvious in the subsequent peeling layer, which is related to the seldom amount of $\mathrm{MoBe}_{12}$, and Mo may also replace $\mathrm{Cr}$ in $\mathrm{Be}_{12} \mathrm{Cr}$ and form $\mathrm{Be}_{12}(\mathrm{Mo}, \mathrm{Cr})$.

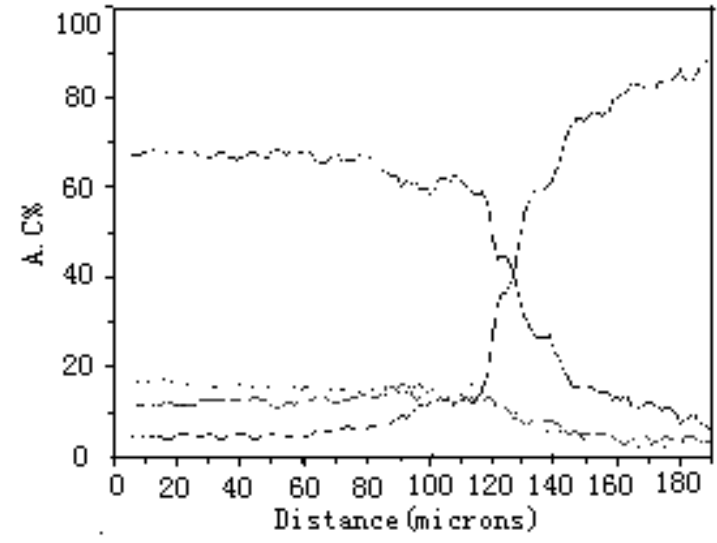

Fig.3 Concentration profile of Be/SS bonding zone

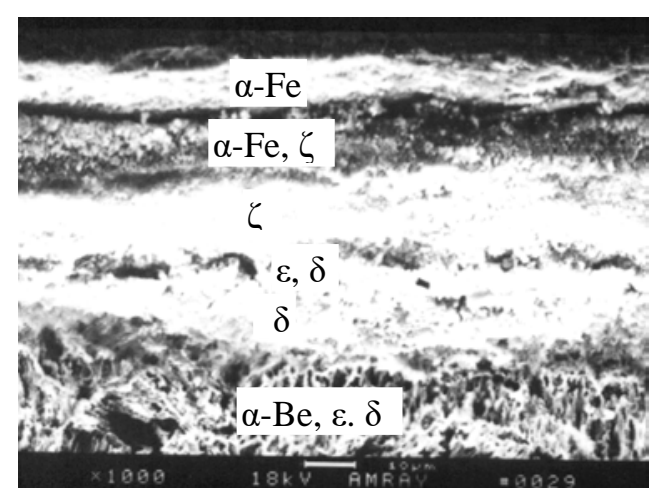

Fig.4 Microstructure of Be/SS bonding zone

Fig. 4 shows that the diffusion bonding zone is lamellar structure, which are almost parallel and 
perpendicular to the outside forces direction. Be/SS diffusion bonding involves more than five element system, it is difficult to exact judgment of these lamellar structures. However, Be and $\mathrm{Fe}$ are main elements in the components. Based on the results of XRD phases analysis, the majority are the phases in Fe-Be binary phase diagram[10]. The microstructure of Be/SS diffusion bonding zone shows in Fig. 4, which is in agreement with the Fe-Be binary phase diagram[10]. Its bottom network structure is respectively the two-phase mixing zone of $\alpha$-Be and $\mathrm{Be}_{11} \mathrm{Fe}(\varepsilon)$, and $\mathrm{Be}_{5} \mathrm{Fe}(\delta)$ and $\mathrm{Be}_{12} \mathrm{Fe}(\varepsilon)$. Because $\alpha$-Be is not corrosion-resistant and $\mathrm{Be}_{11} \mathrm{Fe}$ is corrosion-resistant, the black and white mesh is formed after sample corrosion. Single-phase $\delta\left(\mathrm{Be}_{5} \mathrm{Fe}\right)$ and $\zeta\left(\mathrm{FeBe}_{2}\right)$ are corrosion- resistance, which locate respectively at lower bright band and upper bright band of the middle in Fig. 4. The narrow black belt between two bright bands is the two-phase region of $\delta$ $\left(\mathrm{Be}_{5} \mathrm{Fe}\right)$ and $\zeta\left(\mathrm{FeBe}_{2}\right)$. Because differences in chemical potential, $\alpha$-Be and $\zeta\left(\mathrm{FeBe}_{2}\right), \alpha$-Be and $\delta\left(\mathrm{Be}_{5} \mathrm{Fe}\right)$, and $\delta\left(\mathrm{Be}_{5} \mathrm{Fe}\right)$ and $\zeta\left(\mathrm{FeBe}_{2}\right)$ form respectively two phase original battery, it is reason that two-phase region is not corrosion-resistant. The black and white zone between the upper bright band and the middle bright band is the two-phase region of $\zeta\left(\mathrm{FeBe}_{2}\right)$ and $\alpha$-Fe in Fig. 4, and the upper light band is $\alpha$-Fe.

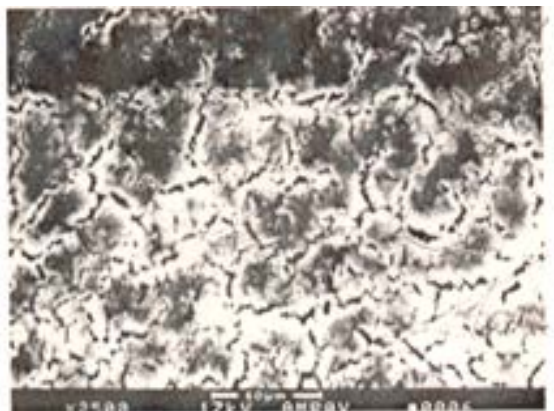

Fig. 5 Cracks and intermetallics on grain boundary of Be/SS joint

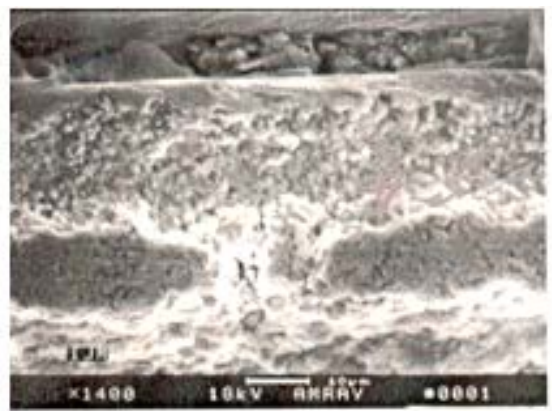

Fig. 6 Diffusion channels on grain boundary of Be/SS joint.

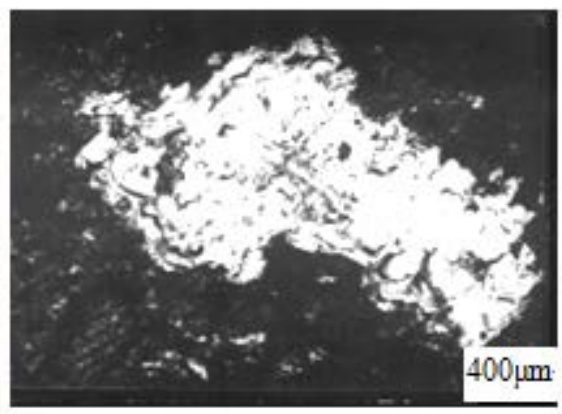

Fig. 7 Fracture morphology of Be/SS diffusion bonding zone

Fig. 5 shows that the small crack of the mesh locates on the grain boundary, and there are some phases or elements segregation on the grain boundary. These mesh shaped grooves may be the main passage of elements delivery. The microstructure after the element diffused along the grain boundary shows in Fig. 6, which is the diffusion channels. The fracture morphology of Be/SS diffusion bonding joint shows in Fig. 7, which is brittle fracture on the grain boundary.

\section{Discussion}

The results of XRD phases analysis for Be/SS diffusion bonding zone show that the elements interdiffusion are not all parts equal to move forward, and there is no single intermetallic compound layer on the interface.

Fig. 5 and Fig. 6 show that the elements diffuse mainly through the grain boundaries, which are the main channel of elements diffusion. The diffusion coefficient in the grain boundary is $10^{3} \sim 10^{6}$ times higher than one in the crystal lattice[11], and the diffusion activation energy in the grain boundary is far less than one in the crystal lattice, so intermetallic compound form firstly on the grain boundary. Once the intermetallic compound forms, it will accelerate the diffusion in the channel. Based on the literature ${ }^{[11]}$, the diffusion coefficients of the intermetallic compounds for $\mathrm{B}_{2}$ type, partial $\mathrm{LI}_{2}$ type, and some other structures are $10^{-3} \sim 10^{-8} \mathrm{~cm}^{2} / \mathrm{s}$, their reaction-diffusion coefficients are $10^{-2}$ to $10^{-7} \mathrm{~cm}^{2} / \mathrm{s}$. The diffusion coefficient of general metals are $10^{-9} \sim 10^{-16} \mathrm{~cm}^{2} / \mathrm{s}$ in the crystal lattice and $10^{-8} \sim 10^{-12} \mathrm{~cm}^{2} / \mathrm{s}$ in the grain boundary, and their surface diffusion coefficient is $10^{-6} \sim 10^{-9} \mathrm{~cm}^{2} / \mathrm{s}[11]$. Because the diffusion coefficient in intermetallic compound is much larger than one in general metal, the diffusion velocity, and the diffusion distance can be increased significantly, and cause the formation of the intermetallic compounds between $\mathrm{Be}$ and $\mathrm{Fe}, \mathrm{Cr}, \mathrm{Ni}$ in beryllium side under $750^{\circ} \mathrm{C} / 50 \mathrm{MPa} / 2 \mathrm{~h}$.

Therefore, the elements diffusion for Be/SS diffusion bonding are mainly through the free surface and the grain boundary. Dissimilar metal atoms gather first gather in the grain boundaries and form intermetallic compounds, then the metal atoms carry on diffusion through the grain boundary or 
intermetallic compounds, and the intermetallic compounds grow up on the grain boundary. Because there are brittle intermetallic compounds and cracks in the grain boundary, the Be/SS diffusion bonding sample is brittle fracture on the grain boundary (see Fig. 5 and Fig. 7). By changing the process parameters or adding an interlayer can avoid forming more brittle intermetallic compounds on the grain boundary, thus improve the bonding performance.

\section{Conclusion}

1)During Be/SS diffusion bonding, Fe and Be form the incomplete solid solution with very little solubility limit, so the dominating way is diffusing along the grain boundaries. The dissimilar metal atoms first gather in the grain boundary and form intermetallic compounds, then the metal atoms carry on diffusion through the grain boundary or intermetallic compounds, and the intermetallic compounds grow up on the grain boundary.

2) During Be/SS diffusion bonding, the elements interdiffusion is not all parts equal to move forward, there is no single intermetallic compound layer in the interface.

3) During Be/SS diffusion bonding, in addition to $\alpha$-Be and $\gamma$-Fe matrix, the brittle intermetallic compounds of Be-Fe, Be-Ni, Be-Cr, and Be-Mo form mainly on the grain boundary, so the Be/SS diffusion bonding specimen is brittle fracture on the grain boundary. By changing the process parameters or adding an interlayer can avoid forming more brittle intermetallic compounds on the grain boundary, thus improve the bonding performance.

\section{References}

[1] Chidambaram Vivek and Wickramanayaka Sunil, Al-Ge Diffusion Bonding for Hermetic Sealing Application, J. Journal of Electronic Materials. 44 (2015) 2387-2395.

[2] Zhang C., Li H.and Li M.Q., Interaction mechanism between void and interface grain boundary in diffusion bonding, J. Science and Technology of Welding and Joining. 20 (2015) 123-129.

[3] Zakipour S., Samavatian M., Halvaee A., Amadeh A. and Khodabandeh A., The effect of interlayer thickness on liquid state diffusion bonding behavior of dissimilar stainless steel 316/Ti-6Al-4V system, J. Materials Letters. 142 (2015) 168-171.

[4] Zhang Yongzhong, Hu Lifang, Meng Qingsen, Wang Wenxian and Liu Wen, Diffusion bonding and interfacial microstructure analysis of AlMgB14-TiB2 to Nb, J. Ceramics International. 41 (2015) 3833-3838.

[5] Zhang C., Li H.and Li M.Q., Formation mechanisms of high quality diffusion bonded martensitic stainless steel joints, J. Science and Technology of Welding and Joining, 20 (2015) 115-122.

[6] Kim Jung Su, Lee Kwang Seok, Kwon Yong Nam, Lee Byeong Joo, Chang Young Won and Lee Sunghak, Improvement of interfacial bonding strength in roll-bonded $\mathrm{Mg} / \mathrm{Al}$ clad sheets through annealing and secondary rolling process, J. Materials Science and Engineering A. 68 (2015) $1-10$.

[7] Satoh Toshikazu and Ishizaki Toshitaka, Enhanced pressure-free bonding using mixture of $\mathrm{Cu}$ and $\mathrm{NiO}$ nanoparticles, J. Journal of Alloys and Compounds. 629 (2015) 118-123.

[8] Dejun Kong and Haoyuan Guo, Analysis of structure and bonding strength of AlTiN coatings by cathodic ion plating, J. Applied Physics A: Materials Science and Processing. 119 ( 2015) 309-316.

[9] Jahn S., Sändig S., Dahms S.and Gemse F., Diffusion bonding systems, J. Materialwissenschaft und Werkstofftechnik. 45 (2014) 807-814.

[10]Dai Yongnian, Binary Alloy Phase Diagrams, Science Press, Beijing 2009. 
[11]Guoliang Cheng and Junpin Lin, Ordered intermetallic compounds based on materials physical metallurgy, Metallurgy Industry Press, Beijing 1999. 